DOI 10.19195/2084-2546.27.20

\author{
ANNA WENDORFF \\ ORCID: 0000-0003-0829-6603 \\ Uniwersytet Łódzki \\ Correo: anna.wendorff@uni.lodz.pl
}

\title{
Construcciones narrativas de los colonos polacos en Misiones. Estudio de caso de Casimira Kotur
}

\author{
Palabras clave: emigración polaca - Misiones - Argentina - estructuras \\ narrativas - identidad narrativa.
}

Al noroeste de Argentina, la provincia de Misiones se presenta como una lengua de territorio argentino con una superficie de $29801 \mathrm{~km}^{2}$, que penetra entre dos países, Paraguay al noreste y Brasil al suroeste. La población de la región procede de una parte de colonos de los dos países vecinos, a los que se suma la migración de alemanes que establecieron sus colonias en el norte, escandinavos y suizos que se asentaron en las partes centrales de la provincia, y polacos y ucranianos que se instalaron en el sur.

La primera emigración campesina de polacos a esa región se data en el año 1897, cuando llega a Posadas (Misiones) un grupo aproximadamente de 15 familias polacas y ucranianas que se instala en la colonia de Apóstoles. La otra ola migratoria de mayor tamaño empieza recién en la mitad de los años 30 del siglo XX, cuando el gobierno de Polonia y Argentina firman un contrato sobre la colonización de Misiones por otro grupo de emigrantes polacos. Desde el año 1936 a Misiones llegan nuevos emigrantes, que luego van a fundar las colonias Wanda y Lanusse.

Es difícil saber el número exacto de inmigrantes polacos en Argentina, pues según el periodo de ingreso muchos llegaron con pasaportes de otras nacionalidades, ya sea por la dominación extranjera de Polonia o en época de guerras. Se cree que unos 6000 inmigrantes entre polacos, ucranianos, checos, rusos y otras nacionalidades fueron conformando las primeras colonias, y que entre los millones de inmigrantes extranjeros que se afincaron en Argentina los 
polacos ocupan el tercer lugar tras los italianos y los españoles. Hoy en día se estima que alrededor de medio millón de argentinos tiene descendencia polaca.

La colectividad polaca en Misiones es de una dimensión importante y compacta. En Misiones muchos pueblos poseen algún club o asociación polaca. En ellos se reúnen familias descendientes de polacos que tienen el interés genuino de mantener las antiguas tradiciones de sus antepasados. Se forman ballets, se elaboran comidas típicas, se trata de mantener el idioma polaco y festejar fechas patrias, como la independencia de Polonia. Los primeros pobladores polacos en el territorio de Misiones construyeron una historia que prontamente se convirtió para ellos mismos en el recorrido de un destino, así como también para sus descendientes en el contexto de los relatos conservados.

En nuestro trabajo queremos analizar cómo se construye la narración de un polaco emigrante, que abordaremos a continuación sobre la base de un caso concreto, el de la Señora Casimira Kotur. Los padres de Casimira nacieron en Polonia, eran polacos étnicos, tradicionales y locales, que se dedicaban a la agricultura. El padre de Casimira, José Kotur, salió de Polonia en 1937 con su hermano Juan de la zona de Kielce hasta Gdynia, y de allí en un barco hasta Londres, después siguió a Estados Unidos y de allí se embarcó a la Argentina. Por su parte, la madre de Casimira, Ladislada Pastusak, salió con sus padres de Lublin en tren hasta Gdynia y después a bordo del barco Batory hasta Casablanca, y de allí hasta Río de Janeiro y más tarde hasta Argentina en 1934 o 1935. Casimira nació ya en la ciudad de Wanda en Argentina.

Antes de continuar con la narración de la historia de Casimira, debemos decir que todo relato lleva indefectiblemente a un estatuto literario y a la vez histórico de entidad. En el ejemplo del relato de la señora Casimira Kotur esto es suficientemente palpable, ya que el texto interior (no escénico) se confronta con su habla exterior, tampoco escénica, pero que la constituye como sujeto polaco / sujeto argentino. Sujeto, según Althusser ${ }^{1}$, que funciona como una entidad ideológicamente definida, y según Benjamin ${ }^{2}$ como históricamente ordenada.

Entendido el relato de esta manera, el personaje de la señora Casimira se coloca a partir de su discursividad en un punto de inflexión que oscila entre la individualidad y la colectividad, dos principios esenciales del orden de los estudios etnográficos, historiográficos, sociales, entre otros. En relación al ejemplo de la señora Casimira, se debe decir que no estamos en presencia de discursividades sociales propiamente dichas, sino por el contrario literarias, con lo cual el sistema de relaciones identitarias y sociales (planteadas a partir de su propio dialogismo) se entremezcla entre lo que está ubicado en el campo de lo social y lo que está en el campo de lo literario. Dicho de otro modo, esta conjunción de estructuras narrativas (identitarias y/o sociales) están

${ }^{1}$ L. Althusser, Ideología y aparatos ideológicos de Estado, Buenos Aires, Ediciones Nueva Visión SAIC, 1984.

${ }^{2}$ W. Benjamin, Sobre el concepto de historia: tesis, apuntes, notas, variantes, Buenos Aires, Piedras de Papel, 2007. 
presentes y actúan como una inmanencia, marcadas por dos tipos de narrativas y dos tipos de narraciones, las literarias y las sociales. Incluso, podemos agregar que lo hacen desde una perspectiva transformada en un marco, y activadas en el contexto del patrón que la modernidad ha impuesto en el sistema que nos rodea, la estructura: sujeto - objeto. Por lo tanto, el sistema de relaciones sociales que las personas se plantean ante tal orden derivan en otras concepciones de vida, y por supuesto en otro sistema de valores.

Conforme a estas contingencias teóricas, debemos afirmar que Casimira es una persona/personaje que se trueca a la vez en sujeto colectivo y en sujeto individual. Por un lado, elabora un perfil sobre la "polaquidad" argentina y a la vez sobre la "argentinización" de los polacos, mecanismos que fluctúan entre la resistencia y la deriva. Resistencias a la transformación, derivas a la consustanciación del sujeto. Si bien para Derrida ${ }^{3}$, el sujeto así como la metáfora están en retirada, en este caso (el ejemplo de Casimira) el sujeto se diluye para invertirse en otro (otra metáfora, otro cuerpo, otra entidad, otra lengua).

La primera categoría que trataremos aquí será la de identidad narrativa, enunciada por Paul Ricoeur y entendida como una narración de la propia vida, una aprehensión de la vida presentada en forma del relato. Dicho de otro modo, se refiere a la identidad que el ser humano alcanza a través del relato cuando este opera dentro de la función narrativa ${ }^{4}$. En todo relato se construyen identidades narrativas, tanto en la ficción como en el relato histórico. Entre el relato histórico y el relato de ficción existen diferencias importantes, no solo referidas a la estructura narrativa del relato en sí, sino también en cuanto al manejo de la temporalidad presentes en un texto. Visto desde cierta perspectiva, ficción e historia actúan del mismo modo cuando de ellas se desprende la descripción de un acontecimiento. Así, la ficción narra una historia que puede contemplar acontecimientos acaecidos en el marco de la realidad o que no están en ella; y por otro lado, la Historia ${ }^{5}$ narra acontecimientos que de modo contrario, pretenden estar siempre en la realidad, pero que también en ocasiones contempla hechos ficcionalizados. No obstante, Ficción e Historia no son estructuras discursivas idénticas, y no se expresan del mismo modo.

Es posible encontrar entre ambos tipos de discurso, que entre ficción $\mathrm{y}$ realidad se conjunten identidades que proporcionen al lector $\mathrm{y} / \mathrm{o}$ al oyente momentos que pertenecen a la verdad, a lo acontecido en la realidad, y, al contrario, momentos que estén en el marco dentro del contexto de la fícción pura, de la ficcionalidad del relato. En todo caso, en ambos se crean identidades, y en ambos discursos se perfilan y se definen, se describen esas identidades. Ahora bien, a partir de este debate, la pregunta que inmediatamente

3 J. Derrida, La desconstrucción en las fronteras de la filosofía: la retirada de la metáfora, Barcelona, Paidós, 1989.

${ }^{4}$ P. Ricoeur, Sí mismo como otro, Madrid, Siglo XXI, 1996.

${ }^{5}$ La Historia (real) en mayúsculas se diferencia de la historia en minúsculas que contempla todo relato fictivo. 
surge es: ¿cómo funciona este concepto de identidad narrativa en Casimira? Veamos cómo inicia su texto:

O sea, no sólo polacos, sino descendientes de polacos (...) yo a veces... a veces... así... estoy pensando que... ¡ ieh! Que nuestros padres vinieron... y es como tragieron [sic] la semilla aquí... plantaron... y formaron raíces crecieron plantas... y... y volvieron a tener más hijos y más hijos... po(r)que uno por ahí se va... viste... por ejemplo a veces me voy al centro... por ahí a... comprar algo... que... o algunas chicas que trabajan en la oficina... ¡ay! ...dice... yo también soy descendiente de polaco... y yo también soy descendiente de polaco... hay, hay mucha gente... (inaudible) ... yo digo que... la gente polaca se desparramó por todo el mundo...6

Como se puede ver, en este primer fragmento, la señora Casimira establece un cuerpo de enunciados que subtitulan la construcción del sujeto individual y de su identificación colectiva. Como sujeto que ha emigrado de su país natal, Casimira ha construido una doble identidad. Primero una identidad que está expresada a través de su yo-identitario, y segundo un yo expresado en un yo-colectivo.

Casimira ha dicho "yo a veces... a veces... así... estoy pensando que... ¡eh! Que nuestros padres vinieron... y es como tragieron [sic] la semilla aquí... plantaron...", este "yo... a veces", por ejemplo, marca un punto de inflexión sobre la construcción de un modelo ficcional, que está fundado a su vez en una identificación personal. Casimira es el personaje del relato y, como tal, la voz narrativa que en este caso particular actúa en primera persona. Pero a su vez, rápidamente Casimira abandona ese discurso personal, para entrar en otro que actúa en un orden identificado con un/su colectivo. Esta segunda estructura se refiere al colectivo de los polacos que viven en Misiones, pero también al de todos los polacos, los que históricamente son de Polonia. Así afirma: "yo también soy descendiente de polaco... y yo también soy descendiente de polaco... hay, hay mucha gente... (inaudible) ... yo digo que... la gente polaca se desparramó por todo el mundo...".

Veamos que aquí estamos en presencia de un doble juego que actúa de manera unísona: juntando al primero, el yo-individual y uniéndolo con uno segundo, el yo-colectivo, Casimira nos dice: "yo también soy descendiente de polaco... y yo también soy descendiente de polaco...".

Digamos algo más. Casimira ha utilizado la forma "viste". Agregar esta palabra al texto no cumple ninguna función en relación a la sintaxis, o a la forma expresiva que contiene la cadena oracional propiamente dicha. En realidad, "viste" forma parte de un uso particular del español argentino, un marcador discursivo conversacional que evoca una llamada propiamente narrativa. Con la inserción de este marcador Casimira está enfatizando dentro del relato la veracidad del mismo y la significación que para ella tiene lo que podríamos

${ }^{6}$ C. Kotur, Entrevista personal, Wanda (Misiones-Argentina), 12 de febrero de 2015, min. 00:00-01:09. 
calificar de narracional. De esta manera, "viste" une narración-ficcionalizada junto a Historia-de-verdad, redistribuyendo las formas al constituirse primero en persona-narrativa, y a la vez en sujeto-histórico. Casimira parece reconocerse como mujer que vive en un universo doble tratando a la vez de identificar el origen de su comunidad y el de su yo individual.

A pesar de haber vivido en Argentina toda su vida y haber nacido allí, la construcción yoica entendida de tal manera como lo planteara Julia Kristeva ${ }^{7}$ en su libro Extranjeros para nosotros mismos, se halla completamente escindida. Ese "yo" dividido está presente tanto si es en función de sí misma, como si fuera parte del contexto. En suma, el sujeto se deconstruye de sí mismo, y la escisión ocurrida junto a la del sujeto-histórico opera como un detonador tanto de la identidad como de la comunidad.

La complejidad hace que el discurso de Casimira inicialmente se vuelva oscuro para el investigador, porque actúan allí algunos factores distintos a los que la identidad cultural define. El primero de ellos tiene que ver con la idea de las geografías étnicas ${ }^{8}$, que se refiere a un proceso de identificación y configuración en el imaginario del actor social de un país, un lugar al cual pertenezco, o me pertenece. Hay una categoría de la cual surge la noción de geografía étnica que se construye a partir del enunciado fronteras étnicas (fronteras entre diferentes grupos étnicos), deriva analizada y presentada por Leopoldo J. Bartolomé en su libro sobre los colonos de Apóstoles. Para este antropólogo, la identidad étnica es capaz de distinguir entre diferentes grupos étnicos, ya que se trata de una relación entre nosotros y los otros. Bartolomé apunta:

\footnotetext{
A pesar de que la diferencia cultural pueda ser importante en el mantenimiento de fronteras étnicas, las tradiciones culturales por sí solas no pueden explicar la persistencia de grupos étnicos, pues en muchos casos la identificación étnica no depende de ningún interés particular consciente en una herencia cultural ${ }^{9}$.
}

En relación con lo que plantea Leopoldo Bartolomé y de acuerdo con lo dicho por la señora Casimira ${ }^{10}$, se puede entonces afirmar que cohabitan en su discurso las nociones de geografía étnica y de frontera étnica. La primera actúa como corolario de su identificación y asociación étnica, es decir los polacos; y la segunda, la de frontera étnica, la relación/diferencia entre polacos y argentinos. La segunda (la frontera étnica) no está presente (o al menos no es visible) en su discurso, en su narración.

${ }^{7}$ J. Kristeva, Extranjeros para nosotros mismos, Esplugues de Llobregat, Plaza \& Janés, 1991.

${ }^{8}$ Cuando decimos geografias étnicas, nos referimos específicamente a que la construcción de la noción de identidad no está sustentada por el espacio geográfico del cual puede ser originaria.

${ }^{9}$ L.J. Bartolomé, Los colonos de Apóstoles: estrategias adaptativas y etnicidad en una colonia eslava en Misiones, Posadas, Editorial Universitaria, Universidad Nacional de Misiones, 2007, p. 186.

${ }^{10}$ Véase la primera cita en la página anterior de este artículo. 
Resulta plenamente admisible, pues, que la persistencia de una se funda en la de la otra, todo eso movido además por la idea ricoeuriana de identidad narrativa. Así podemos notar que para Casimira hay una sola forma de dar cuenta de ello, y se halla en principio en el contexto de su memoria, que permanece en silencio (a no ser que se estimule su habla como en la entrevista), y en segundo lugar, cuando la narración se inicia para un rescate exterior de su historia. Por otro lado, si atendemos a la narración misma, a la voz, a la descripción que se va desplegando a lo largo del relato, esta se constituye enaltecida por la melancolía y la añoranza. Ello nos parece de singular importancia, porque el relato no sólo está marcado por su textualidad, sino porque además se revaloriza en un contexto escénico. Hablar en público debe constituirse en un acto de voluntad, pero sólo en la acción escénica (presentarse ante alguien, hablar en una reunión) implica una convocatoria que descubre las máculas que posee la identidad.

Aunque son entidades diferentes, frontera geográfica y frontera étnica pueden compartir un espacio o aparecer de manera que se muestren una vinculada a la otra. En cualquier caso, aquí no ocurre esta mezcla. Para Casimira no hay una frontera, pues fueron sus padres los inmigrantes, y no ella. Pero este hecho no tiene implicación directa para que ella misma se considere extranjera. Ya veremos resueltamente cómo más adelante durante la entrevista, cambia de lengua (ya hablando en polaco) perdiendo su sentido originario, retribuyendo al valor de poder hablar una lengua tan compleja como el polaco una pertenencia a esa cultura que se pone en duda.

El discurso etnográfico hace parte de sí, aquel texto que se manifiesta como auténtico, pues la voz narrativa del que habla no es susceptible de cuestionamiento. En este sentido, utiliza la narración como una herramienta que da fe del acontecimiento, que es un descriptor que ahonda introspectivamente. Pero tan pronto como el discurso se vuelve "fraudulento", el inofensivo personaje que pasa la prueba de tener un doble (soy uno y soy otro), en la multiplicidad lingüística de la narración, hace que en ese mismo momento la narración empiece a comportarse en sí misma como componente de una parte ficcional. Sigamos con el testimonio de Casimira y veamos que acto seguido (al hablar del padre y de la madre) la persona delimita el perfil de su identidad a través del discurso mismo. Veamos entonces, como lo elabora Casimira Kotur:

Y bueno mis papás vinieron... mi papá vino en el año 35 (ruidos de la calle, coches, tránsito, la entrevistadora cierra la puerta para hacer audible la grabación) sí... mi papá vino primero... mi papá vino en el año $34,35 \ldots$ no estoy muy bien segura pero vino antes que mi mamá, y él se instaló en Wanda, en el puerto de Wanda ${ }^{11}$ y él... cuando venía el barquito, le recibía la otra gente y... y mi mamá... vino en el año 39 con sus papás, mi papá. Mi papá tenía 24 años, mi mamá tenía 13 años, y... mi papá quedó en Wanda, mi mamá se fue con sus papás a Lanusse, y después eh... mi mamá quería trabajar... o sea se enamoró de mi papá (énfasis)

${ }^{11}$ Notemos que en la grabación la Señora Casimira pronuncia la "w" de manera adecuada y no como una semivocal (eue), es decir Wanda como /Vanda/ y no como/Uanda/. 
no sé cómo... porque estaban en Lanusse en Wanda y..., po(r)que era lejos de... y... y bueno y mamá yo no sé cómo ella se conoció con mi papá, la cuestión es que apenas mamá tuvo 16... 17 año(s) ella fue a Wanda a trabajar en la administración... trabajaba como empleada, cocinaba, lavaba la ropa... para la gente que era de la colonizadora... ${ }^{12}$

Parece estar claro que el criterio identitario sobre el que se cierne el discurso, traspasa el nivel primario de identificación. Casimira es de aquí, pero también es de allá. ¿Qué significa esto? ¿Qué es en esencia ser de aquí y a la vez ser de allá? Cuando Casimira empieza a explicar el recurso que la sigue modelando como extranjera o más bien como polaca, aunque nunca descarta su nacionalidad argentina, hace que nuestro centro de atención se mueva hacia una revisión de los papeles sociales o roles que asumimos de acuerdo con el carácter de inmigración, y por otro lado nos trasladamos hacia aquello que hemos querido definir como una polifonía territorial. Retomando la tesis de Althusser ${ }^{13}$, la propia estrategia de construcción social, su papel social, la transforma en sujeto ideológico devenida del que le ha sido expropiada, en su tierra, es decir Polonia.

Ahora bien, para ver adecuadamente estas intervenciones primero debemos retomar algunos criterios de Bartolomé Leopoldo cuando afirma que "las fronteras étnicas persisten a pesar del flujo de personal que las cruza o de la cantidad de interacción que se realiza" 14 en ellas - agregamos nosotros-. Así que todo esto nos lleva a entender el sentido del concepto polifonía territorial. Parece evidente que el cuerpo de Casimira actúa en el centro de esa polifonía, y que como tal surge de una voz dialógica. El cuerpo habla construyendo un nivel narrativo, nivel narrativo que oscila entre un espacio real, un espacio mitificado y un espacio construido.

El otro contexto que se asoma aquí a través del discurso de Casimira tiene que ver con la Compañía Colonizadora del Norte, S.A. y sus diferentes influencias en esta múltiple condición que se sume en la visión del colonizado, además de transformar el contexto en el que se desenvuelven. El desarrollo y evolución histórica de Wanda es la fuente de concreción de narrativas como las de Casimira y tantas otras personas como ella.

En relación con ello, es referencia obligada el libro de Horacio M. Belastegui ${ }^{15}$, Los colonos de Misiones. Belastegui expone las condiciones en las cuales se fueron transformando las zonas de Wanda y cómo evolucionó el carácter comercial de la región. Según Belastegui, "para 1936, a escasos cincuenta kilómetros de Puerto Iguazú, la Compañía Colonizadora del Norte S.A. fundó la colonia Wanda, con inmigrantes polacos, y a unos treinta kilómetros al este

${ }^{12}$ C. Kotur, op. cit., min. 01:24-03:45.

${ }^{13}$ L. Althusser, Filosofía y marxismo, entrevista por Fernanda Navarro, México, D.F., Siglo XXI, 1988, p. 70.

${ }^{14}$ L.J. Bartolomé, op. cit., p. 186.

${ }^{15}$ H.M. Belastegui, Los colonos de Misiones, Posadas, Editorial Universitaria, Universidad Nacional de Misiones, 2006. 
de ella, la colonia Juan J. Lanusse (en homenaje al Gobernador colonizador de

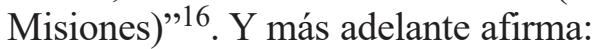

Para mediados de la década del cuarenta, Wanda tenía un puerto habilitado, atención médica, tiendas y almacenes privados, depósitos y galpones de la Compañía Introductora de Buenos Aires donde se almacenaba el tabaco Kentucky y varios aserraderos. Los colonos de Wanda y Juan J. Lanusse plantaron tabaco, tung, cítricos y los restantes cultivos de subsistencia. El Estado Nacional a medida que la colonia crecía construyó escuelas, centros de salud, registro civil y un puesto de Gendarmería Nacional ${ }^{17}$.

Recordemos que Casimira Kotur dice que sus padres trabajaron inicialmente en la Colonizadora ${ }^{18}$, de manera que la acción de los pobladores polacos y su relación con los distintos cuerpos de acción social y trabajo debieron ejercer influencias que tuvieron un profundo impacto en los integrantes de la comunidad. Cabe recordar que los primeros misioneros jesuitas durante la época colonial habían impuesto un ejercicio de dominación sobre los guaraníes y los habitantes de la triple frontera, hecho que dejó una singular y profunda huella de resistencia entre los que después quedaron asentados en esas tierras. Pero si esto evidentemente fue así y si la colonia polaca quiso mantener al máximo las costumbres, la cultura y sus tradiciones en una tierra que por excelencia era totalmente diferente (y lo sigue siendo), los frecuentes desencuentros no debieron hacerse esperar.

Anteriormente nos hemos referido a esa tonalidad melancólica de Casimira, y probablemente se deba a que inclusive el sistema de relaciones entre los mismos habitantes de la colonia y de Wanda constituyó un puente de relaciones que se estableció para superar significativamente el marco de dependencias que se había generado con mecanismos en el par amo-esclavo. Casimira se refiere a los dueños de la colonia (el título no es para menos significativo) como personas que ayudaron de una forma importante a su esposo, que le dieron buen trato y trabajo, y le otorgaron un pedazo de tierra para trabajar. Sin embargo, la formación de este sistema y esta relación social contribuyó a sostener un modelo que puede equipararse con otros, en los cuales los sistemas de dependencia entre los miembros de la comunidad se plantea como una relación de sujeción y por ende de dominación sustentada en los habitantes originarios y transferida a los nuevos miembros de la comunidad.

La línea narrativa que lleva Casimira la va identificando progresivamente tanto consigo misma como con sus raíces. En un momento determinado de la entrevista observamos que Casimira decide cambiar de lengua (sin exactamente declararlo) y da inicio a su discurso en polaco, mezclando ocasionalmente palabras en español por falta de poder expresarse adecuadamente en la lengua de sus padres. Con todo, a pesar de no vivir en un contexto lingüístico polaco,

\footnotetext{
16 Ibidem, p. 93.

${ }^{17}$ Ibidem.

${ }^{18}$ Obviamente se refiere a la Colonizadora del Norte.
} 
sorprende que lo hable con bastante fluidez y de una manera bastante correcta. Este cambio de código lingüístico, que la lejanía y la dificultad del idioma no le impida expresarse adecuadamente en ambas lenguas nos lleva a plantearnos nuevamente si estamos ante una escisión, bifurcación de su identidad, o más bien una reunión de dos identidades. Casimira avanza en su discurso sorteando las dificultades fonéticas de la articulación del fonema interdental fricativo sordo / $\theta /$ o del grupo fónico /ad/ para la palabra administración, o incluso su terminación -ción nos llevan a comprender el grado de asimilación de una otredad vacía $\{\varnothing\}$, pero que manifiesta en el contexto de la identidad la presencia de otra discursividad que surge en y desde Casimira. Por otro lado, cuando cambia de lengua, su cadencia rítmica nos permite expresar que no hay una deconstrucción identitaria. Veamos un ejemplo que parece ser bastante claro al respecto:

la cuestión que tenían su casa linda... su... eh... patiecito... todo y ahí también mi papá les ayudaba mi papá trabajaba... seguía trabajando con ellos... plantaba... eh... arreglaba casitas para conejos... tenía conejos... tenía plantas con fruta... y después eh... (pausa larga) después eh... compraron la... no ... no tan así, compraron la chacra pero vivían la... porque habían un almacén de la Colonizadora en Lanusse (baja la voz) y ahí mis papás vivían en una piecita, tenían una piecita, aparte tenían una cocina que tenía... eh... la cocina de ellos era... eh... piso de tierra y tenían eso... árboles eh...takie drzewo...eh... tizones acá le dicen... (dirigiéndose a la entrevistadora) no sé como usted dice... tizones, ponían tres o cuatro así junto (ø) y ahí se quemaba y la olla colgante y ahí (risas) cocinaba ella... ella con mi papá y el otro dormitorio había otra pareja... eh... que ya no me acuerdo bien cómo... cómo era un nombre también tenían hijos y vivían ahí y bueno... después mi mamá tenía gallinas criaba y un gato onza venía a la noche rompía el tejido entraba en el gallinero mataba las gallinas y después ellos compraron la chacra (...) y vivíamos ahí... (...) una tela que sembraban tabaco y decían rozannik (...) y bueno había bichos ese... dzikie koty taki bili que kury przychodzili zabijać que... $i$ (y) sarny ... y así... tygrys byto blisko domu que zabit psa $i$... i... także ze zmiezili pero taka bieda byta tam na kolonij...mi... moje mama była zwyczajna takie z Polsce... i tato też $i$... y bueno yo... oni jakoś sobie (inaudible) rado... manioky sadzili... bataty... eh... i sałaty mieli... mieli ogród... pero byto ciężko na chacra... tylko czas herbata i herbata i mleko (...) $i$ manioky że jadto... i moja... moja ciocia nie brata tam do domu do nich troche... $i$ tato chodzit moja mama ... eh... w domu była... ${ }^{19}$.

Como se puede ver a través de esta discursividad múltiple y combinada, de esta polifonía, Casimira no intenta retomar una deriva, hablando en términos de Derrida, sino, al contrario, busca recuperar un centro, volver indistintamente a una centralidad que parece estar perdida en términos de sus construcciones identitarias y de sus narrativas. Esta duplicidad, este cambio entre una lengua y otra no es una división estructural de sí misma, no es y no representa un desencuentro, sino más bien lo contrario. La centralidad de Casimira está sustentada en la condición de duplicidad que conserva el extranjero, el foráneo. Se establecen cambios de posición y perspectiva según los roles que se van asumiendo. Cambiar de lengua significa exactamente eso:

${ }^{19}$ C. Kotur, op. cit., min. 9:30-12:30. 
cambiar de posición y perspectiva en relación con los roles que se van asumiendo. Además, concuerda con el sentido de romper la frontera geográfica e inclusive la étnica. Cuando Casimira nos enfrenta a esa dualidad, entendida para ella como una unidad, está reconstruyendo la fuerza narrativa y descriptiva de su discurso. Usar indistintamente la lengua polaca y la lengua española evidencia lo abarcador y el dominio que quiere significar en todos sus ámbitos. De manera que podemos afirmar que estamos ante los principios expuestos por Bajtín ${ }^{20}$ cuando nos habla de los componentes con los que se forma el enunciado, esto es, la voz, la significación y la comprensión. De todo ello se desprende que los componentes del enunciado nos llevan directamente al campo de la polifonía del discurso (polifonía territorial).

\section{Referencias bibliográficas}

\section{ALTHUSSER Louis}

1984 Ideología y aparatos ideológicos de Estado, trad. A. J. Pla, Buenos Aires, Ediciones Nueva Visión SAIC.

1988 Filosofia y marxismo, entrevista por Fernanda Navarro, México, D.F., Siglo XXI.

BAJTÍN Mijail M.

1986 Problemas de la poética de Dostoievski, trad. T. Bubnova, México, D.F., Fondo de Cultura Económica.

BARTOLOMÉ Leopoldo J.

2007 Los colonos de Apóstoles: estrategias adaptativas y etnicidad en una colonia eslava en Misiones, Posadas, Editorial Universitaria, Universidad Nacional de Misiones.

\section{BELASTEGUI Horacio M.}

2006 Los colonos de Misiones, Posadas, Editorial Universitaria, Universidad Nacional de Misiones.

BENJAMIN Walter

2007 Sobre el concepto de historia: tesis, apuntes, notas, variantes, trad. B. Echeverría, Buenos Aires, Piedras de Papel.

DERRIDA Jacques

1989 La desconstrucción en las fronteras de la filosofía: la retirada de la metáfora, trad. P. Peñalver, Barcelona, Paidós.

KOTUR Casimira

2015 Entrevista personal, Wanda (Misiones-Argentina).

KRISTEVA Julia

1991 Extranjeros para nosotros mismos, trad. X. Gispert, Esplugues de Llobregat, Plaza \& Janés.

RICOEUR Paul

1996 Sí mismo como otro, trad. A. Neira Calvo, Madrid, Siglo XXI.

1999 Historia y narratividad, trad. G. Aranzueque Sahuquillo, Madrid, Grupo Planeta.

${ }^{20}$ M.M. Bajtín, Problemas de la poética de Dostoievski, trad. T. Bubnova, México, D.F., Fondo de Cultura Económica, 1986. 


\section{Narrative structures of Polish settlers in Misiones. The case study of Casimira Kotur} identity.

Keywords: Polish emigrants — Misiones — Argentina — narrative structures — narrative

\section{Abstract}

This paper aims to analyse the narration of Polish emigrants from Misiones (Argentina). It uses the interview method and its various forms: open, individual and uncategorised, as it attempts to analyse the case study of Casimira Kotur, who lives in Posadas. According to the results, discourse acts like narration, and not like single stories only, constructing new models of narrative identity. The presence of Polish emigrants in Misiones points to the concept of territorial polyphony and narrative identities because we can assume that discursive and metadiscursive structures which establish historical and identity relationships — can also be found in narrative structures.

Fecha de recepción: 8.05.2018

Fecha de aceptación: 10.09.2018 